\title{
Adolescencia y las emociones representadas a través del arte
}

\author{
María del Rocío Ripoll Lluquet \\ Valencia, España, UPV, mrocioripoll@gmail.com
}

\begin{abstract}
Resumen
Ser adolescente no es fácil. Necesitan ser aceptados por la sociedad, sentirse útiles. En cambio, la sociedad se empeña en rechazarlos. Sus palabras rara vez cuentan, y sus conocimientos no están lo suficientemente arraigados para aportar algo a la sociedad. Por ello, sufren, ven cercana la soledad, y rara vez expresan sus miedos, sus dudas.
\end{abstract}

Es muy importante para el adolescente sentirse seguro y apoyado por los demás. Por ello, la escuela, por su parte, ha de enseñarles a saberse expresar y a saber escuchar. Psicólogos como René Diekstra y Howard Gardner, comparten la idea de un cambio en la manera de educar. En las escuelas, se les suele privar de una educación social, artística y emocional. El aprendizaje artístico debe girar en torno a proyectos; y éstos, dar lugar a esa reflexión, motivación, creatividad.

Nos encontramos con un proyecto de innovación que incorpora una propuesta didáctica en el contexto académico donde se lleva a cabo. En este proyecto, al adolescente se le anima a profundizar en la búsqueda de sus sentimientos y a saber expresarlos a través del arte. Se hace hincapié en el lenguaje audiovisual como medio de expresión, en la que los adolescentes puedan expresar sus sentimientos y emociones a través de la técnica de Stop motion. Al no tener que expresarlos con palabras, se pierde el miedo al rechazo y el proyecto se convierte, inconscientemente, en el alma del adolescente. Con sus obras se vuelven más transparentes.

Este proyecto se llevó a cabo en el colegio Chamberí maristas con adolescentes, que pudieron exteriorizar sus problemas a través del lenguaje audiovisual.

En las escuelas, debe primar el esfuerzo por una educación creativa. Porque la clave del futuro es motivar al adolescente. Así, el educador Ken Robinson, hace referencia a la animación como una herramienta excelente para ayudar al desarrollo de la creatividad de los adolescentes. 
Palabras clave: Adolescencia, creatividad, Stop motion, secundaria, identidad, educación, innovación, formación, sentimientos, emociones, arte.

\section{Introducción}

Allá donde las palabras no alcanzan, la imagen cobra un gran protagonismo, al ser ésta capaz de transmitir lo que con ellas es difícil de explicar.

Ser adolescente no es fácil. Atraviesan una etapa de constantes y rápidas transformaciones, ya sea psíquica o físicamente hablando. El ser adolescente es egoísta, indeciso, y vive en una constante duda sobre qué camino seguir. Surgen miedos por el presente que les toca vivir, así como por el futuro que viene. Necesitan ser aceptados, sentirse útiles, encajar en la sociedad, pero en cambio, la sociedad sin darse cuenta les rechaza, les bloquea. Sus palabras rara vez cuentan, y sus conocimientos sobre la vida no son suficientes para aportar algo a esta sociedad. Todo esto hace del adolescente un ser inseguro, que se refugia en sí mismo y surge el temor por expresar sus dudas, por abrirse a la sociedad; a veces ligado a una ausencia de respuesta o a la incapacidad de saberse expresar.

Nos encontramos con este proyecto, donde se anima al adolescente a expresar sus emociones y sentimientos a través del arte, de forma consciente y a su vez jugando con el subconsciente. Se aborda este tema que tanto preocupa y en el que psicólogos como René Diekstra y Howard Gardner comparten su opinión sobre la privación a los alumnos del aprendizaje social y emocional, y la falta de aprendizaje artístico que dé lugar a la reflexión y motivación, así como a la creatividad. Con ello, el proyecto habla de ausencia, de melancolía, de adolescencia.

Se hizo un ejercicio en el colegio Chamberí Maristas con alumnos de secundaria, los cuales fueron capaces de exteriorizar sus problemas a través de un medio audiovisual, como lo fue en este caso el Stop motion; sin necesidad de palabras, sin desacuerdos.

Utilizamos la animación como medio para expresar los sentimientos e ideas de estos adolescentes, debido al gran protagonismo que la imagen está teniendo en nuestros días. Cada vez más, las palabras se quedan atrás si hablamos de la imagen. Así pues, un buen uso de ella, ayuda a captar la atención del espectador y se llega a su vez a la representación de uno mismo a través de ella. Observando, no solo se puede conocer al artista, sino a todo lo que conlleva.

Así pues, se les explica a los adolescentes la técnica del Stop motion y se les anima crear composiciones donde ellos son los protagonistas, donde reflejen sus sentimientos, dudas y preocupaciones; siendo así sinceros, artistas y creativos. 


\section{Objetivos}

Dado que hacemos referencia a adolescentes, se presupone por tanto la madurez del alumnado para tratar temas delicados como podría ser la melancolía. Una melancolía entendida como la incomprensión hacia ciertas cosas, de ciertas personas, de un mundo cambiante que se les queda pequeño, o quizás grande; donde el refugio no existe para algunos, y la soledad en cambio abre camino en sus vidas.

Centrando la atención en los objetivos, serán los siguientes:

1- Desarrollar la creatividad

2- $\quad$ Recurrir al lenguaje plástico para poder transmitir nuestros sentimientos.

3- Dar un giro a la forma de enseñar arte, ya que muchas veces se les priva a los adolescentes del aprendizaje social y emocional; dando lugar a la reflexión, motivación y creatividad.

4- Crear una vía de expresión en la que el adolescente se pueda abrir al mundo sin necesidad de palabras.

5- $\quad$ Aprender a interpretar las distintas formas de expresión arística.

6- $\quad$ Comprender la complejidad de la creación audiovisual.

7- Analizar los distintos sentimientos y sus posibles formas de comunicarlos por un medio audiovisual.

8- $\quad$ Reflexionar sobre la idea de sentimiento.

9- $\quad$ Aprender a interpretar las distintas maneras de expresión visual.

\section{Desarrollo de la innovación}

Insolencia, impaciencia, despreocupación; connotaciones negativas achacadas durante décadas a la representación del adolescente. Adolescencia como tiempo de refugio, de cambios costantes, de rebeldía. G. Stanley Hall describe la adolescencia como un período de "tormenta e ímpetu". Llena de cambios, en la que el adolescente entra en la búsqueda de su identidad.

El adolescente está en contínua necesidad de intentar aceptarse. Ante la no aceptación del adolescente, surge esa necesidad de aferrarse a algo o a alguién, la necesidad de pertenecer; y cuando esto desaparece, se sienten de nuevo perdidos, aislados; la soledad llama de nuevo a su puerta. Todo esto ligado a la inseguridad y el miedo al rechazo que sienten, les lleva a no llegar a expresar sus dudas o sentimientos. Por eso, es muy importante por nuestra parte, sobre todo por los educadores, hacerles sentir ese apoyo y comprensión que tanto necesitan. 
La escuela pues, ha de formar personas capaces de saberse expresar, personas de saber escuchar; y ha de cambiar su forma de educar en cuanto al arte nos referimos. Pues hoy en día, en las escuelas se les suele privar de aprendizaje social y emocional, así como del aprendizaje artístico. Mientras, se cree que la educación es cada vez más libre y no se está teniendo en cuenta la censura creativa a la que se les somete a los propios alumnos. Se les enseña a no fallar y están programados a aprenderse las cosas tal cual les vienen; se les enseña a copiar, más no a imaginar. Esto es un error, ya que desde niños, se cuenta con el don de la creatividad, y sin darse cuenta las escuelas lo van apartando poco a poco. La creatividad pues, no debería quedarse al margen, ya que al igual que triunfa el que más sabe, muchas veces eso implica ser el que más arriesga, y el que más arriesga normalmente es el que más innova, y no se puede pues, innovar sin tener un cierto aire de creatividad en el cuerpo. Éste aprendizaje artístico, debería girar en torno a proyectos que dieran lugar a esa reflexión, motivación y creatividad del alumno. Es por ello que este proyecto educativo aborda el tema de creación de una vía de expresión en la que los adolescentes puedan abrirse al mundo sin necesidad de palabras, tan solo a través de la representación visual y audiovisual. Que sean capaces de transmitir sus sentimientos y emociones a través de un medio audiovisual; de transmitirlos al mundo exterior de una manera consciente y a su vez jugando con el subconsciente.

En nuestra sociedad, donde lo visual está cada vez más presente, un buen uso de los medios audiovisuales ayuda a captar la atención del público espectador. Artistas como Motomichi Nakamura, opinan que la animación es una de las vías que utilizan los artistas para poder comunicar sus ideas. A través de una imagen se puede llegar a reflejar uno mismo; entendiendo a la imagen como alma del autor. A través de ella podemos conocer a la persona, ya que con ésta es más fácil de expresar sentimientos que con frecuencia no se comunicarían con palabras. Así, entendemos la animación como un recurso artístico importante, el cual proporciona al adolescente facultades y oportunidades de superar obstáculos y transmitirslos al mundo exterior de forma precisa y sin la necesidad de palabras.

Así pues, nos encontramos ante un proyecto de animación en el cual se anima al adolescente a profundizar en sus sentimientos y emociones y a saber plasmarlos y transmitirlos a la sociedad de forma artística y creativa, como lo es en este caso, a través del lenguaje audiovisual, a través de la técnica del Stop motion.

Poco a poco, y a través del Stop motion, el adolescente va registrando composiciones que representan su mundo, lo que permite acercarse a ellos. Conocerlos, escucharlos, y animarlos a expresar sus sentimientos sin miedo al rechazo de la sociedad que les rodea, es una de las principales premisas de este proyecto de innovación e investigación. 


\subsection{Metodología empleada}

En este proyecto se han utilizado distintas metodologías. Entre ellas encontramos, la clásica magistral y la más utilizada en antaño; la tutoría proactiva, no muy conocida, en la cual el docente anticipa la información necesaria sobre el tema que los alumnos puedan necesitar en el futuro; y la metodología de investigación, la cual ocupa un puesto importante.

Si tenemos en cuenta que una de las intenciones es la de hacer comprender a los alumnos que en esta etapa tan difícil, como lo es la adolescencia, no se encuentran solos, sino que ellos mismos comparten sentimientos y sensaciones; y haciéndoles ser conscientes de ello, podría tenerse en cuenta aquí también el uso de una metodología de trabajo cooperativo, con el fin de que sientan apoyo mutuo.

Al principio se hace hincapié en el tema a tratar, dada su gran importancia. Se pretende llegar así a los alumnos de una forma más cercana. Posteriormente, se han estudiado diferentes referentes artísticos en la que se aprecia que también ellos han pasado por esta época de melancolía. Se anima pues a los alumnos a acercarse a ellos, y a conocerles mejor, a través de su estudio.

La segunda parte de este proyecto de investigación e innovación consiste en la producción audiovisual por parte de los jóvenes bajo la técnica del Stop motion. Ésta técnica es la elegida al ser tan cercana para todo tipo de público. Siempre teniendo en cuenta que la finalidad es que los adolescentes transmitan sus sentimientos y emociones en esta obra visual y audiovisual, y así comunicarse con el mundo exterior sin necesidad alguna de palabras.

\section{Resultados}

El adolescente rehúye las explicaciones, vive en constante duda y apenas se reconoce en el ayer. Ese miedo constante al rechazo, a no ser aceptados, conlleva a no decir ni una palabra, a no dejar entrever sus pensamientos. Se podría entender mejor al adolescente, cuando las palabras no son sinceras, si se pudiera leer el pensamiento. Y se puede. Ese miedo a la incomprensión conlleva a la prudencia. Prudencia de no hablar más de la cuenta, de no dejarse ver quien es.

Por eso, el trabajo artístico juega un papel importante, donde el adolescentebaja la guardia, existe cierta relajación, e intenta llevar a cabo de la mejor forma posible su proyecto. Reflexiona, medita, lo que conlleva a plasmar aquello que siente de una forma casi precisa. El miedo al rechazo desaparece al ser la imagen la que da sentido al trabajo. Ésta, viene siendo el alma del alumno, donde queda reflejada de forma inconsciente. 
A través de los videos realizados, una parte de la adolescencia queda reflejada en ellos. Es tanto así que cada trabajo es único y cobra una fuerza importante en la que conociendo un poco al autor, te das cuenta que solo él podría haber creado esa obra. Con ella, el adolescente se vuelve más accesible, más transparente.

Entre los trabajos artísticos destacamos:

THE WIRE MAN, el miedo a no poder cumplir lo que se espera de nosotros, la necesidad de comprensión, de no sentirnos solos.

DAY DREAM, se agradece a la comprensión amiga ante el dolor producido por la falta de reconocimiento, en un mundo gris poco dado a ello.

LA INFANCIA PERDIDA, aborda la frustración ante la vida que nos rodea, haciendo hincapié en la esperanza de un futuro mejor, aquí en forma de rescate.

Ideas que se repiten; soledad, incomprensión, consuelo, amor, dolor, añoranza, huida, esperanza, reconocimiento, melancolía. Una forma de acercamiento a la psicología adolescente y a su propia personalidad. Aunque mañana, ya no sea la misma.

En la exposición de cada trabajo se adjuntan imágenes del mismo y la explicación del autor o autores en letra cursiva. Nuestra interpretación, a veces poética, siempre didáctica, a tono con el proyecto propuesto. Se acompaña también un enlace a cada vídeo, para poder visualizarlos. A continuación, se exponen algunos de los proyectos resultantes.

\subsection{Day Dream}
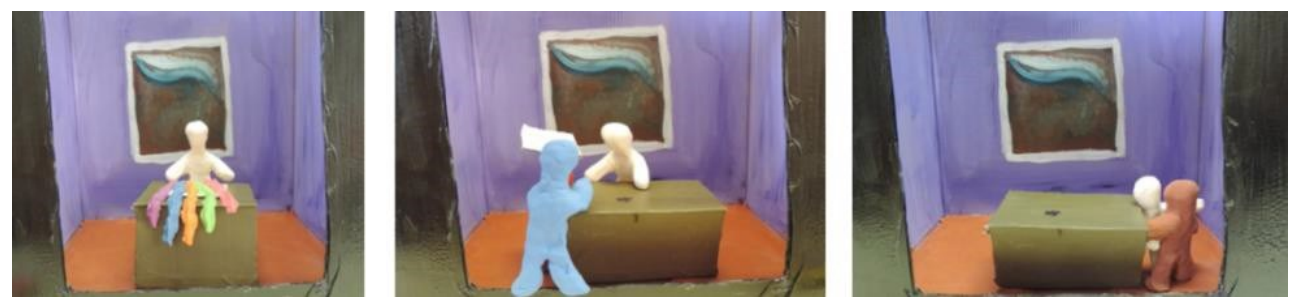

Fig.1;Fig.2;Fig.3; M,M-M,A Day dream, 2016. Stop motion. Disponible en: $<\underline{\text { https://youtu.be/TrHUnYaYX3w }>}$

"El corto refleja la realidad de la sociedad. El muñeco blanco representa a aquellas personas que tienen ideas maravillosas y vanguardistas, pero el resto de la sociedad (representada por el muñeco azul), no te dejan llevarlo a cabo. Por ello hay tanta gente oprimida, pero, si alguien te ayuda a salir de ello (muñeco marrón), podrá triunfar el amor frente al miedo".

El gris, gris de mediocridad. La sociedad le ha elegido para decorar sus carencias. Cualquier otro color desentona a su lado. Pero las personas tienden a veces en su 
individualidad a contradecir su colectividad. Se esfuerzan, se afanan por destacar, por consolidar su personalidad y su trabajo en ese mundo anodino al que pertenecen. Un mundo convaleciente de envidia que no favorece los reconocimientos ajenos a la vez que lucha por los propios. Competencia voraz; otra vez la mediocridad campando a sus anchas. El no reconocimiento de una labor bien hecha puede ser sinónimo de hundimiento. Y sumisión a la tiranía. Se echa en falta la mano amiga; y a veces llega. La comprensión, el agradecimiento o el amor son antagónicos a la mediocridad, y las mejores armas para combatirla. No hay que tener miedo al desprecio si estamos seguros de nuestro trabajo, aunque no haya elogio, mientras aún quede amor.

\subsection{La Infancia Perdida}

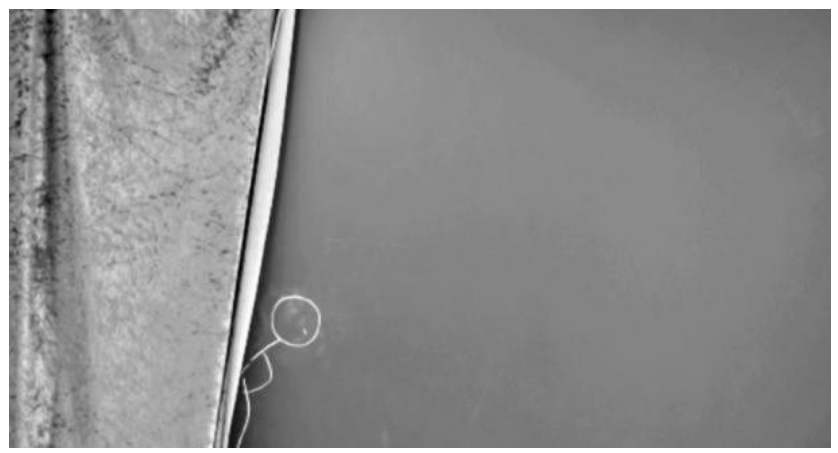

Fig. 4 D,A.-G,M.La infancia perdida, 2016. Stop Motion. Disponible en:

$<\underline{\text { https://youtu.be/5v8av7jWs90 }}>$

"Nuestro trabajo como temática principal a tratar es la melancolía. Una melancolía vista desde los ojos de una chica, en la que la vida que le rodea es gris, apagada, llena de sufrimiento y tristeza. Recurre desde su imaginación a un mundo onírico y fantástico para recuperar aquel sentimiento de indiferencia ante el mundo que la rodea, reviviendo así aquella infancia que perdió al crecer. En el Stop motion aparecen símbolos como el dragón de la historia interminable haciendo referencia a la película visualizada cuando somos niños, y la planta con doble sentido, simboliza la maduración mental de la persona”.

Alex forma parte de la fantasía animada. Es la protagonista, la chica melancólica ante la vida que le rodea. Necesita aislarse, protegerse, armarse; del entorno, con coraza, de valor. Otra vez los recuerdos salen al rescate como elementos presentes en la trama. Michael Ende, la historia interminable y Fújur, el dragón de la suerte. Salva a la chica del mundo gris, el mundo triste, el mundo anodino. Y es curioso que el rescate se produzca al final de la madurez mental, al final de la adolescencia. Es significativo y nada reconfortante; no se puede chillar más alto. Aquí el melancólico se da más cuenta de lo que verdaderamente le rodea cuanto más madura. "Si no pienso, no me entero". Pero el adolescente piensa, y se pregunta, y a veces no halla respuestas, o las que halla no le satisfacen. En el pensamiento 
melancólico casi siempre hay un futuro mejor que se añora; y no se espera. Huir puede ser la solución; pero no siempre acude Fújur al rescate.

\subsection{The Wire Man}

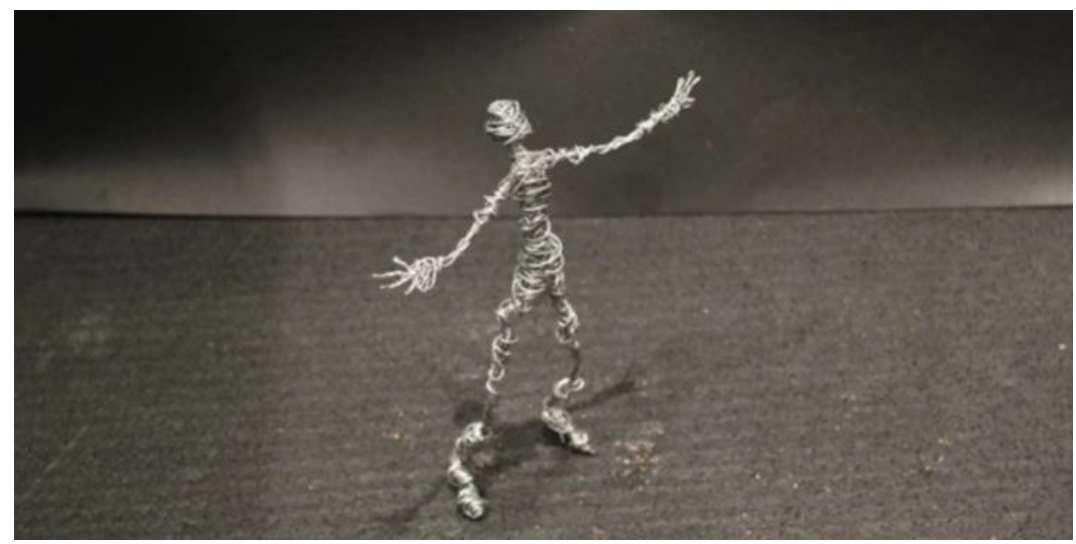

Fig.5 A,A-B,I: The Wire Man, 2016. Stop Motion. Disponible en: $<\underline{\text { https: } / / y o u t u . b e / J 6 D r B I M c-G s}>$

"El tema principal de este proyecto es la melancolía relacionada con la adolescencia. Nos hemos centrado en el sentimiento de soledad. Durante la etapa de la adolescencia muchos jóvenes sienten incomprensión y mucha presión al ser incapaces de cumplir los roles sociales establecidos. En un principio se puede apreciar como nuestro personaje crece, inspirándonos en el nacimiento de una mariposa al salir de su crisálida. En el momento en el que consigue levantarse, se percata de su soledad, y da vueltas buscando a alguien que esté a su alrededor. ...

Antes de hacerlo estuvimos mirando varios cortos de animación para inspirarnos y hubo uno en concreto que nos llamó la atención, un corto llamado Coda. Narra la historia de un pobre borracho que muere atropellado al salir de una discoteca, su alma no tarda en encontrarse con la Muerte, con la que intenta negociar desesperadamente antes de sucumbir finalmente al sueño eterno. Ese corto refleja la soledad que siente el hombre cuando muere e intenta aferrarse a la vida".

Soledad, motivo de melancolía. Al tema de la incomprensión, se añade la presión por no poder cumplir lo que se espera de nosotros. Falta de concentración, de dedicación, y el pensamiento en otro lugar, que lastra el rendimiento. Quizá aún no sabemos exactamente qué se espera de nosotros. El sentimiento de soledad se percibe al madurar; y en la adolescencia se necesita comprensión, y para que ésta exista y se perciba no podemos sentirnos solos. 

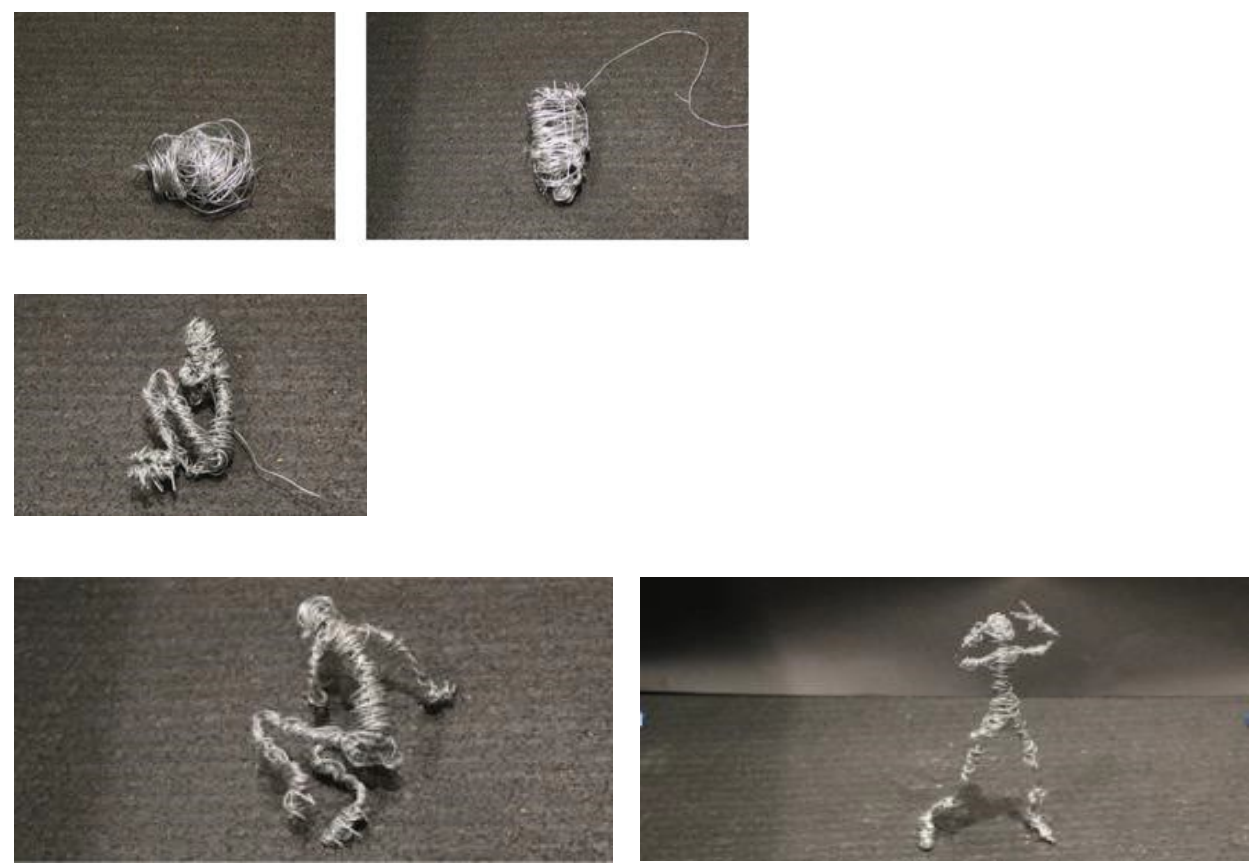

Fig.6; Fig.7;Fig.8; Fig.9; Fig.10 A,A-B,I: The Wire Man, 2016. Stop Motion.

\section{Conclusiones}

Soy consciente de lo difícil que puede llegar a resultar en la adolescencia la exteriorización de los problemas, por no saber expresarlos, o no atreverse a contarlos. Por eso se ha hecho hincapié en la labor orientadora del docente, en la que se intenta escuchar al adolescente no solo con palabras, sino a través del lenguaje audiovisual, empleando así el arte como medio de expresión. Haciéndoles ser artistas, creativos, sinceros.

Por ello, este proyecto de innovación, es a su vez una propuesta educativa, en la que empleando el arte como medio de expresión, se anima a los adolescentes a profundizar en la búsqueda de sus sentimientos. Así pues, por medio del lenguaje audiovisual, los adolescentes han exteriorizado de forma subconsciente problemas existentes, siendo posible facilitar la ayuda necesaria para la resolución de los mismos.

Considero pues que la creatividad no hay que dejarla al margen, y que es muy importante tratar a cada alumno de manera personal y distinta. Quizás, enseñándoles a ser un poco libres en su manera de aprendizaje, y enseñarles a aprender mediante proyectos, quizás así crezcan más genios creativos capaces de innovar y de sentirse seguros de sí mismos, aun sabiendo que son distintos al resto. 
Con respecto a la técnica empleada en el estudio con adolescentes, fue un acierto debido a su gran capacidad para captar la atención del espectador, así como la de su propio autor. Es un técnica muy recurrida para llevarla a cabo en el aula y nada mejor que la animación para dar un toque creativo a la enseñanza y la forma de aprender las cosas.

\section{Referencias}

ARNETT, J. J. (1999). “Adolescent Storm and Stress” en American Psycologist. American Psicological Association. Vol 54, No 5. 317-326.

$<$ http://www.jeffreyarnett.com/Arnett_1999_AmPsy.pdf> [ Consulta : 5 de enero de 2018].

ARNETT, J. J. (2000). "Emerging Adulhood, A Theory of Development From the late Teens Through the Twenties" en American Psycologist. American Psicological Association. Vol 55, No 5. 469-480.<http://www.jeffreyarnett.com/articles/ARNETT_Emerging_Adulthood_theory.pdf $>$ [Consulta : 5 de enero de 2018].

ARNHEIM, R. (1997). Arte y percepción visual. Madrid, España: Alianza Editorial.

AYMERICH, C Y M. (1976). Expresión y Arte en la Escuela 2 : la expression plástica. Barcelona : Teide.

BORDIGNON, N. A. (2005). "El desarrollo psicosocial de Eric Erikson. El diagrama epigenético del adulto" en Revista Lasallista de Investigación [en línea] Vol 2 No 2 $<$ http://www.redalyc.org/articulo.oa?id=69520210 $>$ [ 18 de Julio de 2016].

Et al., (2006) Dinámicas de creación y procesos terapeúticos. Universidad de Murcia : Imprenta Valle C.E.E.

DURÁN, G., SÁNCHEZ, J. (1954) La psicología de los artistas. Madrid : Espasa-Calpe. ERIKSON, E. (1998) O ciclo de vida completo. Porto Alegre : Artmed.

EISNER, E. W. (2004). El arte y la creación de la mente : el papel de las artes visuales en la transformación de la conciencia. Paidós.

GOMBRICH, E. H. (2002). Arte e illusion : estudio sobre la psicología de la representación pictórica. Londres : Phaido Press Limited.

Hall, G.S.(2011). “Adolescencia” $\quad$ En :rtve.es, Tres14.

$<$ http://www.rtve.es/alacarta/videos/tres14/tres14-adolescencia/978777/>. [Consulta : 3 de diembre de 2017]

KILEY, D. (1983). The Peter Pan Syndrome : Men who Never Grown Up. London : Corgi Books.

ORTIZ, A ; PIQUERAS, M. J. (1995). La pintura en el ciné : Cuestiones de representacion visual. Barcelona : Ediciones Paidós ibérica. 
RIPOLL, M.R. (2016). Adolescencia y Melancolia: Proyecto de educación con técnica de Stop Motio (Trabajo de fin se máster). Universidad autónoma de Madrid, España.

ROBERT, J., STENBERG AND TODD, J. LUBART. (1995). La creatividad en una cultura conformista : un desafio a las masas. Barcelona : gráfiques 92, S.A.

ROBINSON, K. (2011). Out of our minds : Learning to be creative. United Kingdom : Capstone publishing.

RUIZ,. (2014). La animación como herramienta didáctica. Tesina fin de master. Madrid : Universidad Autónoma de Madrid.

SAÉNZ VALIENTE, R. (2006). Arte y técnica de animación, España : Ediciones de la flor.

SELBY, A. (2009). Animación : Nuevos proyectos y procesos creativos. Barcelona : Parramón ediciones.

TAYLOR, R. (2000). Enciclopedia de la animación : una guía compléta de técnicas paso a paso acompañada de una notable muestra de obras terminadas. Barcelona : editorial Acanto. 